\title{
A pseudolymphomatous reaction in soft tissue associated with phenytoin sodium
}

\author{
J. N. WILDEN AND C. A. SCOTT
} From the Departments of Surgery and Pathology, Royal United Hospital, Combe Park, Bath, BA1 3NN,
UK

SUMMARY A pseudolymphomatous reaction involving subcutaneous tissue and underlying skeletal muscle is described in a woman who was receiving phenytoin sodium and phenobarbitone. The histological appearance was of nodular, densely cellular tissue composed of histiocytes, plasma cells, lymphocytes, fibroblasts, and occasional polymorphonuclear cells. The significance of this finding is briefly considered in relation to the existing literature.

Numerous side effects and toxic reactions result from the use of anticonvulsants. Glaser (1972) has listed at least 16 types of toxicity to hydantoins, one of which is the pseudolymphomatous reaction involving lymph nodes. These have been described by several authors (Merritt and Putnam, 1939; Coope and Burrows, 1940; Saltzstein and Ackerman, 1959; Bajoghli, 1961; Rosenfeld et al., 1961; Björnberg and Holst, 1967). Others (Hyman and Sommers, 1966; Gams et al., 1968; Tashima and de los Santos, 1974) report the development of malignant lymphomas after hydantoin therapy, some of which did not regress on withdrawal of the drug. Epidemiological evidence suggests that more lymphoma patients are receiving chronic phenytoin therapy than would be expected by chance (Anthony, 1970; Charlton and Lunsford, 1971).

Clinically, the pseudolymphomatous syndrome consists of lymphadenopathy, fever, exanthematous eruption, eosinophilia, and, less frequently, hepatosplenomegaly. The histological appearance of the typical lymph node has been well described by Saltzstein and Ackerman (1959).

\section{Case report}

A 31-year-old farmer's wife presented in July 1975 with painless swellings in the right submandibular, lumbar, and scapular regions. She had been taking $100 \mathrm{mg}$ of phenobarbitone and $200 \mathrm{mg}$ of phenytoin sodium daily for seven years to control her psychomotor epilepsy. In 1967 the patient was diagnosed

Received for publication 12 January 1978 as suffering from multiple sclerosis. Similar swellings in the right and left submandibular regions had occurred in 1970. On that occasion the swelling was soft and fluctuant, aspiration was unhelpful, radiology of the region was normal, and the swelling disappeared within six weeks of her starting a course of penicillin.

On admission to hospital in August 1975 the swelling in the right lumbar region had already disappeared. Apparently it had persisted for only two weeks. The swelling at the angle of the right mandible had enlarged over a period of two weeks, was not tender or inflamed, and had begun to diminish slowly in size. After a further two weeks the patient noticed a similar swelling at the lower border of the right scapula. She also complained of an irritable hot feeling on the back but there was no arthralgia or rash. Examination revealed that she was afebrile, there was no cervical, axillary, or inguinal lymphadenopathy, nor was there a rash or hepatosplenomegaly. The swellings were soft, mobile, and non-tender, they did not transilluminate, and the swelling in the region of the right scapula measured approximately $3 \times 4 \mathrm{~cm}$. There were no other physical signs apart from neurological ones. The swelling at the lower border of the right scapula was removed. It was of fatty consistency and extended from subcutaneous tissue into muscle.

ESR, full blood count, chest radiograph, urea and electrolytes, plasma calcium and phosphate, and autoantibodies (immunofluorescent technique), including antinuclear factor, were normal. White cell count was $4.8 \times 10^{9} / 1\left(4.8 \times 10^{3} / \mathrm{mm}^{3}\right)$. A peripheral blood film showed $6 \%$ eosinophils, $18 \%$ lymphocytes, 
$68 \%$ neutrophils, and $8 \%$ monocytes. Liver function tests showed slightly raised globulins; subsequently, both IgG and IgM were found to be increased, at 18.7 $\mathrm{g} / \mathrm{l}$ and $3 \cdot 2 \mathrm{~g} / \mathrm{l}$, respectively, though $\mathrm{IgA}$ was normal (normal range of IgG is 6-15 g/l and for IgM 0.5-2.5 $\mathrm{g} / \mathrm{l})$. Whole blood folate was $84 \mu \mathrm{g} / 1(84 \mathrm{ng} / \mathrm{ml})$ (normal range 200 to $450 \mu \mathrm{g} / \mathrm{l}$ or $\mathrm{ng} / \mathrm{ml}$ ). Serum phenobarbitone levels have ranged between 19 and $83 \mu \mathrm{mol} / \mathrm{l}(4.4$ and $19.3 \mathrm{mg} / \mathrm{l})$ (therapeutic range 40 to $150 \mu \mathrm{mol} / 1$ or 9.3 to $34.9 \mathrm{mg} / \mathrm{l}$ ) and serum phenytoin levels have been no greater than $9 \mu \mathrm{mol} / 1(2 \cdot 2 \mathrm{mg} / \mathrm{l})$ (therapeutic range 35 to $80 \mu \mathrm{mol} / 1$ or 8.7 to $20 \mathrm{mg} / \mathrm{l}$ ). An EMI scan revealed generalised cerebral atrophy with an area of cystic change at the right occipital pole, possibly representing an old infarct.

\section{HISTOPATHOLOGY}

Macroscopically, five soft irregular brown masses were obtained, the largest being $20 \times 12 \times 10 \mathrm{~mm}$.

Microscopically, the sections showed nodules of extremely cellular tissue separated by bands of dense fibrous tissue (Fig. 1). The nodules were composed of numerous histiocytes, lymphocytes, and fibroblasts with scattered plasma cells and occasional polymorphonuclear cells (Fig. 2). Some histiocytes were multinucleated (Fig. 3). The dense infiltrate was arranged haphazardly, and in the nodules capillaries and small arterioles were plentiful, as were reticulin fibres. Neither foreign material nor Langhans' giant cells with caseation were identified. In addition, very few mitotic figures were seen, and Reed-Sternberg cells were not found. The little skeletal muscle present was enveloped by the inflammatory process with destruction of some of the muscle fibres.

\section{Discussion}

This case has three unusual features. The swellings were not associated with the typical pseudolymphomatous syndrome, they resolved spontaneously without the withdrawal of phenytoin, and the reaction occurred outside lymph nodes. The lesion removed from the scapular region had the histological features of a pseudolymphomatous reaction, and the patient's phenytoin therapy is possibly related to the development of this swelling. Similar, though not identical reactions have been observed occasionally in patients not receiving any form of drug therapy. For example, Helwig and Hansen (1951) described benign lymphoid polyps of the rectum, and Saltzstein (1963) pseudolymphomas of the lung. Both lesions had a definite follicular pattern with germinal centres whereas the case described here had a nodular pattern and no germinal centres. The soft tissue lesions reported by Lattes and Pachter (1962) showed the features of well-differentiated lymphoid tissue, which they considered were likely to be either hamartomas or choristomas. In this case there were

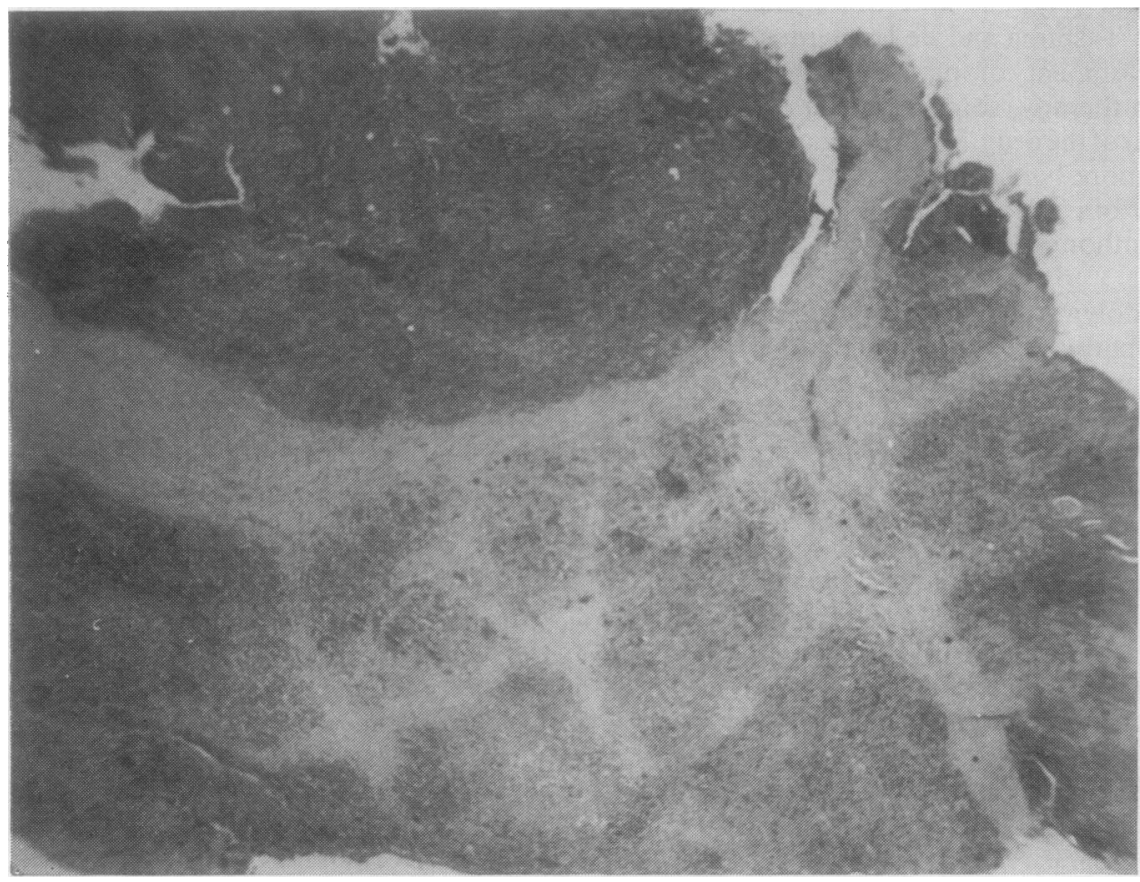

Fig. 1 Low power to show nodules of densely cellular tissue.

Haematoxylin and $\operatorname{eosin} \times 10$. 


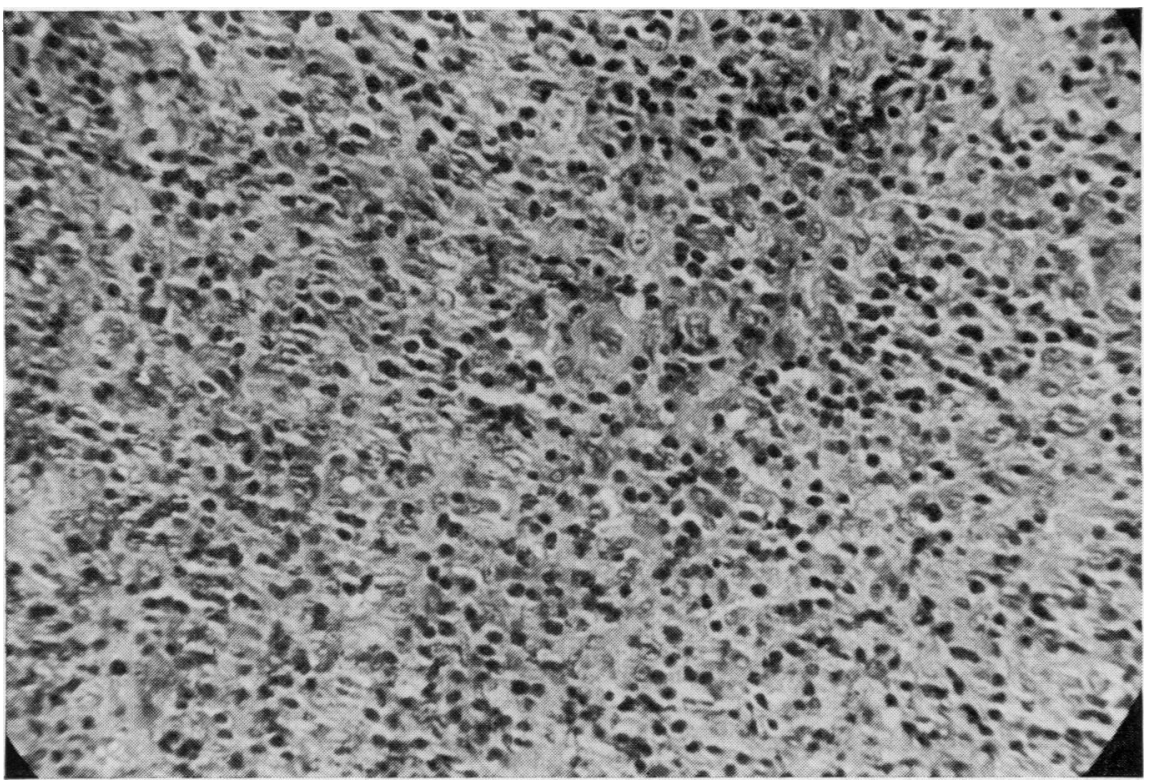

Fig. 2 High

power to show

detail of cellular

infiltrate. $H$ and $E$

$\times 100$.

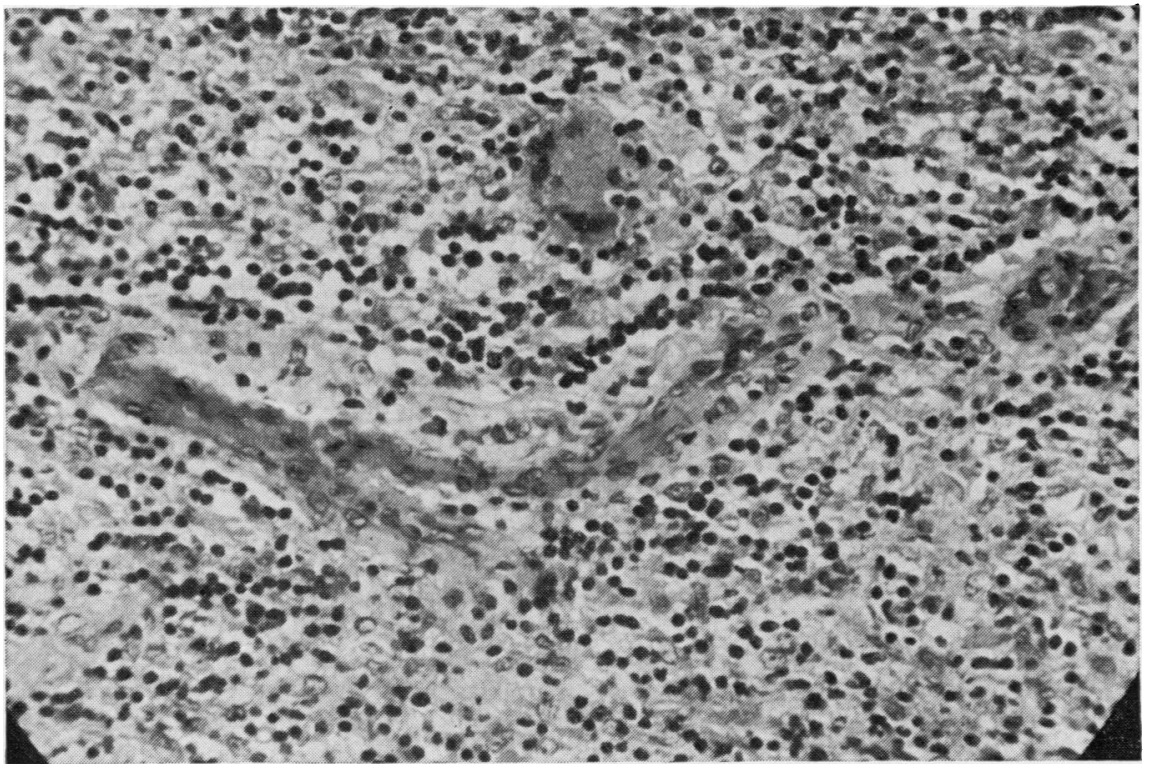

Fig. 3 High

power to show

detail of

cellular infiltrate

including a multi-

nucleated histiocyte

adjacent to $a$

capillary. $H$ and $E$

$\times 100$.

no features to suggest an origin from lymphoid tissue nor that it was a choristoma. However, in order to secure an association between phenytoin and the patient's pseudolymphomatous reaction, a further period of observation will be required to ascertain whether similar swellings occur under the conditions of ingestion and non-ingestion of phenytoin.

Forecasting the patient's clinical course from the histology is difficult (Lancet, 1971). Rosenfeld et al.
(1961) and Doyle and Hellstrom (1963) have each described patients with lymphadenopathy related to the hydantoins which histologically appeared to be lymphosarcoma and Hodgkin's disease, respectively. Both patients have remained in remission since the drug was stopped. However, two of the seven cases reported originally by Saltzstein and Ackerman (1959) as histologically benign subsequently developed malignant lymphomas, even though the 
hydantoins were withdrawn (Clinopathologic Conference, 1962). It should be noted that neither of these cases, from the reports, was ever free of all the stigmata of a lymphomatous process after withdrawal of the hydantoins. Conversely, Gams et al. (1968) have reported a case of malignant lymphoma, considered to be related to diphenylhydantoin, which completely regressed after withdrawal of the drug. Fourteen months later the lymphoma recurred and the patient subsequently died of the disease, though at no stage was the drug reintroduced into the patient's management. However, it could be argued that there were two separate disease processes in action simultaneously, only one of which was related to hydantoin therapy. In view of these reports it is obviously important that patients with pseudolymphomatous reactions undergo long-term followup. In our case, 29 months after presentation, remission has persisted without phenytoin therapy being stopped.

We thank Mr T. L. Schofield, consultant surgeon, Dr G. S. Wakefield, consultant neurologist, Dr J. V. Lever, consultant pathologist (who kindly prepared the photographs), Mrs G. Allen (optician), and Sister Barlow and her staff, from the Royal United Hospital, Bath. We are grateful to Professor N. F. C. Gowing at the Royal Marsden Hospital, London for his histological opinion, to Dr R. L. Hewer, consultant neurologist, under whose care the patient was originally treated, and to Dr J. L. G. Thomson for the EMI scan at Frenchay Hospital. We appreciate the helpful advice of Drs A. Seaton and P. C. Elmes of Llandough Hospital, Glamorganshire. Finally, we should like to thank Mrs P. E. J. Harding for her careful preparation of the manuscript.

\section{References}

Anthony, J. J. (1970). Malignant lymphoma associated with hydantoin drugs. Archives of Neurology, 22, 450454.

Bajoghli, M. (1961). Generalized lymphadenopathy and hepatosplenomegaly induced by diphenylhydantoin. Pediatrics, 28, 943-945.

Björnberg, A., and Holst, R. (1967). Generalized lymphadenopathy as a drug reaction to hydantoin. Acta Neurologica Scandinavica, 43, 399-402.

Charlton, M. H., and Lunsford, D. (1971). Le sostanze di idantoina come possibli cause del linfoma maligno. $\frac{\overline{\mathrm{O}}}{\mathrm{a}}$ (Abstract.) Minerva Medica, 62, 2185.

Clinopathologic Conference (1962). Lymphoma or drug $\underset{\vec{D}}{\stackrel{\bar{S}}{ }}$ reaction occurring during hydantoin therapy for epilepsy. American Journal of Medicine, 32, 286-297.

Coope, R., and Burrows, R. G. R. (1940). Treatment of $\frac{\bar{c}}{\bar{c}}$ epilepsy with sodium diphenyl hydantoinate. Lancet, $1, \underset{\mathbb{Q}}{\overparen{D}}$ 490-492.

Doyle, A. P., and Hellstrom, H. R. (1963). Mesantoin कै lymphadenopathy morphologically simulating $\vec{\circ}$ Hodgkin's Disease. Annals of Internal Medicine, 59, 363-368.

Gams, R. A., Neal, J. A., and Conrad, F. G. (1968). $\stackrel{\omega}{ }$ Hydantoin-induced pseudo-pseudolymphoma. Annals of Internal Medicine, 69, 557-568.

Glaser, G. H. (1972). Diphenylhydantoin toxicity. In Antiepileptic Drugs, edited by D. M. Woodbury, J. K. Penry and R. P. Schmidt, pp. 219-226. Raven Press, $\sigma$ oै New York.

Helwig, E. B., and Hansen, J. (1951). Lymphoid polyps 은 (benign lymphoma) and malignant lymphoma of the rectum and anus. Surgery, Gynaecology and Obstetrics, 92, 233-243.

Hyman, G. A., and Sommers, S. C. (1966). The develop- $\frac{\text { क }}{4}$ ment of Hodgkin's disease and lymphoma during anti- $\vec{P}$ convulsant therapy. Blood, 28, 416-427.

Lancet (1971). Editorial. Is phenytoin carcinogenic? Lancet, 2, 1071-1072.

Lattes, R., and Pachter, M. R. (1962). Benign lymphoid masses of probable hamartomatous nature: analysis of 12 cases. Cancer, 15, 197-214.

Merrit, H. H., and Putnam, T. J. (1939). Sodium diphenyl hydantoinate in treatment of convulsive seizures: toxic $\supseteq$ symptoms, and their prevention. Archives of Neurology $\overrightarrow{\vec{O}}$ and Psychiatry, 42, 1053-1058.

Rosenfeld, S., Swiller, A. I., Shenoy, Y. M. V., and Morrison, A. N. (1961). Syndrome simulating lym-7 phosarcoma induced by diphenylhydantoin sodium. Journal of the American Medical Association, 176, 491-용 493.

Saltzstein, S. L. (1963). Pulmonary malignant lymphomas and pseudolymphomas: classification, therapy, and prognosis. Cancer, 16, 928-955.

Saltzstein, S. L., and Ackerman, L. V. (1959). Lymphadenopathy induced by anticonvulsant drugs and $\mathrm{O}$ mimicking clinically and pathologically malignant $D$ lymphomas. Cancer, 12, 164-182.

Tashima, C. K., and de los Santos, R. (1974). Lymphoma and anticonvulsive therapy. (Letter.) Journal of $\stackrel{\circ}{-}$ the American Medical Association, 228, 286-287.

Requests for reprints to: Dr J. N. Wilden, Department of Neurology, The Churchill Hospital, Headington, Oxford OX3 7LJ. 